УДК 338.46

Каролина КОТУЛЕВИЧ-ВИШИНЬСКА

\title{
УЧАСТИЕ СТРАН ВИШЕГРАДСКОЙ ГРУППЫ В ПРОГРАММЕ «ВОСТОЧНОЕ ПАРТНЕРСТВО»
}

\begin{abstract}
Аннотация. В 2019 г. будет отмечаться десятилетие запуска программы «Восточное партнерство». С ее старта до конца 2012 г. на хорошем уровне функционировало многостороннее сотрудничество в рамках программы. Начиная с 2013 г. прежде всего преобладают двусторонние отношения Европейского союза с восточными соседями. Особое внимание в связи с этим следует обратить на отношения стран Вишеградской группы со странами Восточного партнерства. Несмотря на то что самый большой уровень заинтересованности в программе всегда проявляла Польша, однако Венгрия, Словакия и Чехия также присоединились к реализации целей данной инициативы. И сегодня страны Восточного партнерства занимают важное место во внешней политике Вишеградской группы. Следует учитывать то, что страны Вишеградской группы для восточных соседей могут служить примером трансформации общества, строительства государства и укрепления отношений с Западом. В настоящий момент для вишеградских стран очень важным аспектом сотрудничества со странами Восточного партнерства является укрепление региональных отношений. Общие действия стран В4 могут быть направлены на строительство в странах Восточного партнерства сильного гражданского общества, на поддержку местных инициатив, на развитие независимой журналистики и других начинаний, ведущих к демократизации стран, охваченных проектом. Цель данной статьи заключается в анализе того, какие инициативы страны В4 реализуют в странах Восточного партнерства при помощи Международного Вишеградского фонда и при участии Европейского союза и которые таким образом способствуют реализации вышеупомянутых целей.

Ключевые слова: Вишеградская группа, страны Восточного партнерства, Международный Вишеградский фонд, флагманские инициативы, учебные программы, отношения на межличностном уровне, трансграничное сотрудничество, энергетическая безопасность, сотрудничество в области транспорта.
\end{abstract}

Программа «Восточное партнерство» (ВП), запущенная в мае 2009 г., является частью европейской политики соседства. Ее основной целью служит углубление политических связей и экономическая интеграция Армении, Азербайджана, Белоруссии, Грузии, Молдавии и Украины с Европейским союзом. Программа ВП не

(C) Каролина Котулевич-Вишиньска - кандидат экономических наук, доцент кафедры политических наук Краковского экономического университета. Aдpec: Uniwersytet ekonomiczny w Krakowie, ul. Rakowicka 27, 31-510 Kraków. E-mail: kotulewk@uek.krakow.pl Современная Европа, 2018, № 7 
является последующим этапом расширения Европейского союза. Участие в инициативе не гарантирует в будущем членства, хотя и не исключает его.

Данный проект с момента его ввода в действие подвергается критике со стороны как западного, так и российского экспертного сообщества [Громыко Ал. А., 2015, 272; Борко Ю. А., 2018; Восточное партнерство до и ..., 2014]. В свою очередь страны Вишеградской группы очень положительно относятся к программе «Восточное партнерство». Более того, сегодня Восточное партнерство является для Вишеградской группы приоритетом. Об этом свидетельствуют не только заявления министров иностранных дел В4, но также конкретно предпринимаемые действия по отношению к непосредственным восточным соседям. Страны B4 активно участвуют в реализации общих целей программы ВП, но наибольший интерес на сегодня представляет сфера развития гражданского общества в этих странах. Поэтому страны B4, реализуя данную цель программы, стараются укреплять взаимные отношения на межличностном уровне. Данная инициатива реализуется при поддержке Международного Вишеградского фонда (International Visegrad Fund - IVF), который был создан правительствами Чехии, Венгрии, Польши и Словакии в 2000 г. ${ }^{1}$ Фонд является инструментом, который способствует развитию регионального сотрудничества и на сегодня является единственным совместным институтом стран В4 [Шишелина Л.Н., 2015: 20]. При содействии фонда страны В4 поддерживают и развивают контакты между обществами стран Восточно-Центральной Европы, Западных Балкан и стран Восточного партнерства.

В рамках Фонда действуют грантовые, академические и стипендиальные программы (табл. 1).

Таблица 1

Программы Международного Вишеградского фонда

Программы академические и стипендиальные

\section{Visegrad Scholarship Program:}

- Intra-Visegrad, In-Coming, OutGoing

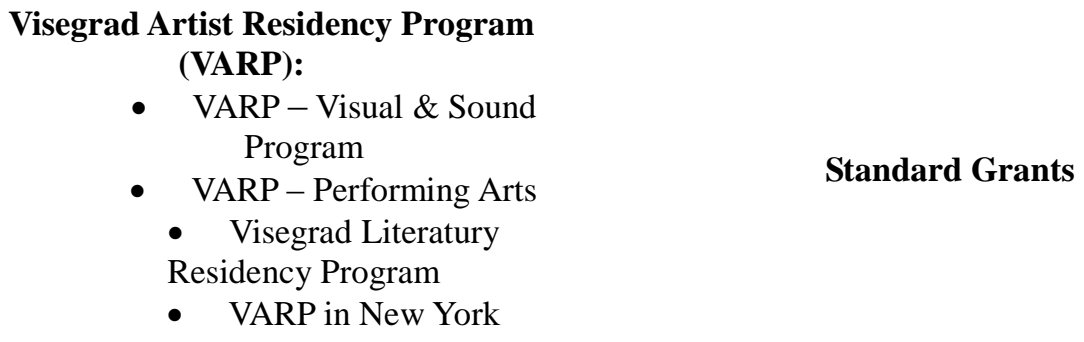

\section{Standard Grants}

Грантовые программы

\section{Small Grants}

\footnotetext{
${ }^{1}$ Деятельность Фонда направлена на содействие развитию регионального сотрудничества в вишеградском регионе, а также между регионом, Западными Балканами и странами Восточного партнерства.
} 
Visegrad University Studies Grants

Visegrad - Taiwan Scholarships

Visegrad Scholarship at OSA
Visegrad Stategic Grants

\author{
Visegrad + (Western Balkans) \\ Visegrad 4 Eastern Parnership \\ Program: \\ - Flagship Projekt \\ - V4EaP (Extended) Standard \\ Grants \\ - $\quad$ V4EaP Visegrad University \\ Studies Grants
}

IVF-NSC Taiwan Joint Research Project

Источник. Международный Вишеградский фонд. URL: https://www.visegradfund.org/ (доступ: 19.11.2018).

Среди перечисленных программ особое место занимают те, которые адресованы странам Западных Балкан (Visegrad +) и странам Восточного партнерства (Visegrad 4 Eastern Partnership). Программа, адресованная странам ВП, была запущена в июне 2011 г. [Joint Statement on the Enhanced Visegrad Group Activities in the Eastern Partnership]. Ее основные цели - поддержка демократии и процесса трансформации, региональное развитие и развитие гражданского общества в странах ВП [The Visegrad Group Foreign Ministers' ...]. Её запуск был своего рода ответом на принятие в Праге в мае 2009 г. проекта «Восточное партнерство». Действия Фонда вписывались в общую стратегию Европейского союза по отношению к странам ВП и отвечали его общему подходу «большее за больше». Как известно, принцип данного подхода сводится к тому, что те страны ВП, которые будут привержены глубоким демократическим реформам, могут ожидать большего от участия в европейской программе. Это стало одним из поводов укрепления сотрудничества между странами Центральной и Восточной Европы [Joint Statement on the Enhanced Visegrad Group Activities in the Eastern Partnership].

Следует заметить, что перед вводом в действие программы Visegrad 4 Eastern Partneship (V4EaP) страны B4 в рамках Международного Вишеградского фонда реализовали на общих условиях проекты в странах ВП. Однако начиная с 2012 г. программа (V4EaP) позволила интенсифицировать действия в области укрепления сотрудничества между субъектами. Это стало возможным в связи с тем, что в ее рамках реализуется широкий ряд проектов, к которым относятся «Флагманские проекты» (Flagship Projects), расширенные стандартные гранты (Extended Standard Grants) и гранты, предназначенные на ведение научных исследований (University Studies Grants). Кроме того, граждане стран ВП являются участниками Visegrad Scholarship Program.

Так, программа «Флагманские проекты» направлена на поддержку долгосрочных проектов стратегического характера и процесса реформирования, политической ассоциации и экономической интеграции с EC, на укрепление институциоСовременная Европа, 2018, № 7 
нального потенциала, построение гражданского общества и предоставление помощи в процессе преобразований странам ВП. Предпочтение отдается проектам неправительственных и некоммерческих организаций, местных органов власти и муниципалитетов, государственных учебных заведений, культурных и научноисследовательских учреждений. В рамках программы к реализации принимаются проекты, в которых участвуют заявители из всех четырех стран В4 и, по крайней мере, из двух стран Восточного партнерства (включая заявителя, если это необходимо) [Rules for the Preparation... the V4EaP Flagship Projects...]. Годовой бюджет составляет 600 тыс. евро [Flagship Projects].

В свою очередь расширенные стандартные гранты (Extended Standard Grants) направлены на поддержку среднесрочных проектов стратегического характера, которые в значительной степени способствуют предоставлению доступа к уникальному опыту «ноу-хау» стран Вишеградской группы в области процесса демократических преобразований, европейской интеграции и регионального сотрудничества [Rules for the Preparation, Selection, Approval and Implementation of V4EaP Extended Standard Grants Financed...]. Данные гранты направлены на поддержку реформ, развитие политического сотрудничества и экономической интеграции с ЕC, на наращивание институционального потенциала, развитие гражданского общества и содействие общему процессу преобразований в странах Восточного партнерства. Проекты, представленные на рассмотрение Фондом, должны содержать информацию о получателе гранта в стране, охваченной программой ВП, и о не менее трех партнерах со стороны стран B4 [Visegrad Fund - 15, 2015: 23].

В рамках университетских исследовательских грантов (University Studies Grants) предоставляются гранты с целью поощрения, поддержки или запуска перспективных курсов и программ обучения в высших учебных заведениях и исследовательских центрах. Согласно правилам Фонда курс должен состоять из серии лекций или семинаров по предмету, посвященному странам В4, результаты которого должны быть включены в программу академического обучения. Такая программа должна состоять из нескольких лекций (минимум 12) или полной описи исследований, являющихся частью учебной программы, которая в определенной степени ориентирована на страны B4 [Rules for the Preparation, Selection, Approval and Implementation of the Visegrad University Studies Grants...]. Грант является единовременным и признается избранным университетским отделом, школами или факультетами, которые могут представить готовый учебный план такого курса (программы) и подтвердить его запланированное долгосрочное включение в свою учебную программу. Курс или программа должны быть долгосрочными [Rules for the Preparation, Selection, Approval and Implementation of the Visegrad University Studies Grants...].

Как было указано выше, страны ВП также могут участвовать в Вишеградской стипендиальной программе (Visegrad Scholarship Program). Она создана с целью содействия академическому обмену путем предоставления финансовой поддержки студентам и исследователям, которые являются гражданами стран В4 и стран ВП. В 
ней могут принимать участие все высшие учебные заведения, аккредитованные министерствами, ответственными за высшее образование, и институты Академии наук [Rules of the Visegrad Scholarship Program].

Вишеградская группа в рамках флагманских проектов, расширенных стандартных проектов, университетских исследовательских грантов в 2006-2017 гг. утвердила к реализации в странах Восточного партнерства 113 проектов (табл. 2). Для сравнения: с 2006 г. и до конца 2017 г. в странах Западных Балкан в среднем было реализовано всего 64 проекта.

Таблица 2

Гранты Международного Вишеградского фонда, реализованные при участии стран В4 и стран ВП в период 2006-2017 гг. $\begin{array}{ccccccccccccc}200 & 200 & 200 & 200 & 201 & 201 & 201 & 201 & 201 & 201 & 201 & 201 & \\ 6 & 7 & 8 & 9 & 0 & 1 & 2 & 3 & 4 & 5 & 6 & 7 & \text { Всего }\end{array}$

Культура и идентичность

Образование и развитие потенциала

Региональное развитие, окружающая среда и туризм

Демократические ценности и средства массовой информации

Государственная политика и институциональное партнерство

Инновации, исследования и разработки, предпринимательст Bо

Социальное развитие

Всего

1

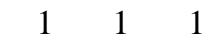

7

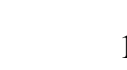

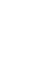

(2)


Доля стран ВП в общем числе заграничных грантов B4, в \%
$33, \quad 50, \quad 18, \quad 10,47,47,50,44, \quad 32, \quad 38, \quad 57, \quad 43, \quad$ (в $\begin{array}{lllllllllllll}3 & 00 & 18 & 00 & 06 & 37 & 00 & 44 & 26 & 71 & 89 & 90 & \text { средне }\end{array}$ м)

Источник. Самостоятельный расчет на основании данных Международного Вишеградского Фонда. URL: https://www.visegradfund.org/ (доступ: 19.11.2018).

В данное время в среднем доля проектов, реализованных в странах ВП, в общем количестве заграничных проектов, реализованных на средства Международного Вишеградского фонда, составляет $39,46 \%$ от общего числа внешних грантов. В общем на реализацию совместных проектов стран В4 и стран ВП Фонд за данный период потратил более 3 млн евро. Страны В4 совместно со странами ВП в 2006-2017 гг. реализовали: на Украине - 70 проектов, в Грузии - 23, в Армении - 11, в Белоруссии -7 , в Молдавии - 2 и в Азербайджане - 1 проект. На Украине было реализовано проектов на общую сумму 1,6 млн евро $(52,09 \%)$, в Грузии соответственно более 878 тыс. евро (28\%), в Армении - 417 тыс. евро (13,29\%), в Молдавии - 122 тыс. евро $(3,88 \%)$, в Беларуси - около 78 тыс. евро $(2,42 \%)$ и в Азербайджане - около 10 тыс. евро $(0,31 \%)$.

В рамках Visegrad Scholarship Program (табл. 3) предоставляются стипендии магистрантам, абитуриентам магистратуры и исследователям всех дисциплин продолжительностью до четырех семестров и возможность участия в 190 программах высшего образования в странах Центральной и Восточной Европы.

Таблица 3

Количество стипендий, выданных гражданам стран ВП в рамках программы Visegrad Scholarship Program в 2006-2017 гг.

$\begin{array}{lllllllllllll}200 & 200 & 200 & 200 & 201 & 201 & 201 & 201 & 201 & 201 & 201 & 201 & \text { Всего }\end{array}$

$\begin{array}{llllllllllll}6 & 7 & 8 & 9 & 0 & 1 & 2 & 3 & 4 & 5 & 6 & 7\end{array}$

Армения

Азербайджан

Беларусь

Грузия

Молдавия

Украина

Всего

$\begin{array}{lllllllll}5 & 3 & 6 & 6 & 3 & 2 & 5 & 6 & 41\end{array}$

$\begin{array}{llllllllll}2 & 4 & 5 & 3 & 5 & 4 & 5 & 6 & 5 & 39\end{array}$

$\begin{array}{lllllllllllll}4 & 6 & 11 & 29 & 28 & 22 & 23 & 21 & 17 & 12 & 10 & 7 & 190\end{array}$

$\begin{array}{llllllllll}7 & 9 & 5 & 5 & 5 & 3 & 6 & 5 & 5 & \mathbf{5 6}\end{array}$

$\begin{array}{llllllllllll}1 & 1 & 7 & 2 & 1 & 4 & 3 & 3 & 3 & 3 & 4 & 32\end{array}$

$\begin{array}{lllllllllllll}28 & 73 & 63 & 67 & 34 & 37 & 35 & 33 & 54 & 54 & 45 & 45 & \mathbf{5 6 8}\end{array}$

$\begin{array}{lllllllllllll}33 & 79 & 75 & 120 & 82 & 73 & 76 & 65 & 84 & 82 & 74 & 72 & 926\end{array}$

Источник. Международный Вишеградский фонд. URL: https://www.visegradfund.org/ (доступ: 19.11.2018).

В 2006-2017 гг., как следует из представленных выше данных, наибольшее количество стипендий было предоставлено гражданам Украины - 61,33\% (568 стипендий) и Белоруссии - 20,52\%. Гражданам остальных стран ВП страны В4 в целом 
предоставили $15,55 \%$. В среднем на Армению, Азербайджан, Грузию и Молдавию Вишеградский фонд выделил 4,54\% от общего количества стипендий, предназначенных для стран ВП.

Начиная с 2012 г. Фонд предоставляет ежегодно 1,0-1,5 млн евро на реализацию проектов, касающихся сотрудничества между странами В4 и странами ВП. С начала действия и до конца 2016 г. Фонд на программы, реализованные в странах Восточного партнерства, выделил 9,2 млн евро, что составляет $12,15 \%$ от общего количества средств. Данная сумма почти в 4 раза больше, чем сумма, выделенная Фондом для стран Западных Балкан (2,2 млн евро, или 2,87\%).

Сегодня сферы совместного взаимодействия между странами Вишеградской группы и Восточного партнерства - это сотрудничество в области транспорта, модернизации транспортной инфраструктуры и трансграничное сотрудничество. Взаимодействие в данной области возможно благодаря созданию в 2011 г. в рамках программы «Восточное партнерство» Транспортной группы ВП, в рамках которой ведется обмен информацией и обмен опытом между странами-партнерами и государствами-членами ЕС. В связи с этим ЕС в странах ВП определил приоритетные инфраструктурные проекты, реализация которых будет способствовать улучшению транспортного сообщения как между странами-участницами программы ВП, так и между странами ВП и ЕС. Данного рода инициативы способствуют интеграции стран ВП с транспортной системой Центральной и Восточной Европы.

Таблица 4

Инвестиции, связанные с реализацией приоритетных инфраструктурных транспортных проектов в странах ВП

\begin{tabular}{lll} 
& \multicolumn{3}{c}{ Количе } \\
& ство & \\
Страна & инфрас & Автодо \\
ВП & труктур & рожные \\
& ных & проект \\
& проекто & \\
& в &
\end{tabular}

Армени

я

Азерба

йджан

Беларус

b

Грузия

Молдав

ия

Украин

a

10

$28 \quad 8$

$\begin{array}{lll}\text { Железн } & \text { Интерм } & \text { Внутре } \\ \text { одорож } & \text { одальн } & \text { нний } \\ \text { ные } & \text { ый } & \text { водный } \\ \text { проект } & \text { транспо } & \text { транспо } \\ \text { ы } & \text { рт } & \text { рт }\end{array}$

$\begin{array}{ll}\text { Морско } & \text { Возду } \\ \text { й } & \text { шный } \\ \text { транспо } & \text { трансп } \\ \text { рт } & \text { орт }\end{array}$

-

Размер

Размер инвест инвести иций ций (млн (млн евро) долл. США) $\begin{array}{ll}628,6 & 716\end{array}$

2

$723,4 \quad 1500$

$110,9 \quad 311$

$540,3 \quad 5711,7$

1601,3

$14 \quad 11 \quad 2$

5

2

2

Современная Европа, 2018, № 7 


$\begin{array}{llllllllll}\text { Всего } & 83 & 45 & 13 & 7 & 1 & 16 & 1 & 10061,06 & 8238,7\end{array}$

Источник. Самостоятельные расчеты на основании данных Европейского Союза. URL: https://ec.europa.eu/transport/themes/international/european_neighbourhood_policy/eastern_partn ership/transport-panel_en (доступ 23.11.2018).

Страны В4 проявляют большой интерес к развитию транспортной инфраструктуры между Европейским союзом и странами Восточного партнерства (так называемым connectivity), которая является одним из приоритетов политики ВП, установленной во время саммита в Риге в 2015 г. Для стран В4 данная сфера сотрудничества важна потому, что она способствует не только укреплению экономических связей, но и усилению политического сотрудничества. Что касается взаимодействия со странами ВП в более широком аспекте, то министры стран В4 предложили, чтобы в рамках инициативы ЕС по сотрудничеству с Китаем, который заинтересован в реализации проекта «Новый шелковый путь», учитывать в соответствии с европейской синергией и другие региональные проекты. В ближайшем будущем ЕС планирует расширить европейский проект TEN-T на страны Восточного партнерства [Joint Statement of the Ministers of Foreign Affairs of the Visegrad Group...].

Что касается вопроса новых транспортных и инфраструктурных сообщений между ЕС и восточными соседями, страны В4 выразили надежду, что для реализации данной цели можно использовать недавно созданный Европейский план внешних инвестиций. Согласно предположению Европейской комиссии можно рассчитывать на новые инвестиции размером 44 млрд евро [Orędzie o stanie Unii 2016 r...]. Для Европейского союза, частью которого являются страны В4, наличие хорошо действующих автомобильных и железнодорожных сообщений, а также энергетических и информационных, это важная область в сфере строительства в регионе стабильности, мира и человеческих перспектив [Nowy wymiar Partnerstwa Wschodniego?]. Вышеуказанная цель соответствует общим намерениям EC, который в новом бюджете на период 2021-2027 гг. планирует реализацию внешних инициатив в рамках Европейского инструмента соседства и Международного сотрудничества и развития предоставить 89,2 млрд евро [Budżet UE...]. Страны B4 проявляют заинтересованность в повышении энергетической безопасности путем диверсификации источников и маршрутов поставок, укреплении региональной интеграции энергетического рынка путем развития инфраструктур для реверсных поставок газа со всеми соседними странами. В соответствии с этим страны В4 заинтересованы в своевременной реализации газового коридора Север-Юг ${ }^{1}$ [Kolejny

\footnotetext{
${ }^{1}$ Газопровод Север-Юг, строительство которого ведется в настоящий момент, соединит в будущем терминал LNG в Свиноустье и проектируемый газопровод Baltic Pipe с планируемым терминалом Adria LNG в Хорватии. Европейская комиссия признала в 2013 г. за данной инвестицией статус проекта, который имеет общеевропейское значение, и поддержала его в 2015 и 2017 гг. Строительство газопровода планируется на 2018-2020 гг.
}

Современная Европа, 2018, № 7 
odcinek Korytarza Północ-Południe...] в направлении Южного газового коридора ${ }^{1}$ [Азербайджан открыл газопровод в Европу...]. Данная инициатива соединит Польшу, Чехию, Румынию, Словакию и Венгрию [Pyziak-Rapacz, 2014: 47-56]. Страны В4 заинтересованы в реализации каждой новой инициативы, которая будет способствовать осуществлению концепции интеграции Южного газового потока с Вишеградским регионом и обеспечит доступ Центральной и Восточной Европы к каспийскому газу. Данная инициатива способна повысить энергетическую безопасность Европейского союза [Joint Statement of the Ministers of Foreign Affairs...].

В рамках данного подхода Вишеградская группа старается взаимодействовать со странами Восточного партнерства. Техническая идея запуска реверсных маршрутов из европейских государств появилась в 2009 г. В ноябре 2012 г. Украина начала импорт газа через Польшу [Украина в мае увеличила импорт...], а с апреля 2013 г. начались его поставки со стороны Венгрии [Украина начала закупать газ...]. С сентября 2014 г. начались поставки газа из Словакии. Итак, начиная с сентября 2014 г. между Словакией и Украиной действует реверсный маршрут, по которому Украина импортирует природный газ. В 2014 г. импорт газа из Словакии на Украину составил 3,6 млрд куб. м, в 2015 г. - 9,7 млрд куб. м, в 2016 г. - 9,1 млрд куб. м, за январь-май 2017 г. - 4,8 млрд куб. м. [Украина за 1000 дней импортировала...].

Также и Молдавия старается проводить диверсификацию поставок природного газа. В 2015 г. между Молдавией и Румынией начал действовать реверсный газопровод Яссы-Унгены. Инвестиции в его строительство составили 26 млн евро, из которых 7 млн евро были взяты из европейских фондов. После строительства компрессорной станции в Румынии и строительства газопровода Унгены-Кишинев протяженностью 130 км Молдова сможет получать по нему из Румынии 1,5 млрд куб. м газа [Молдова начнет завтра импорт...].

Министры стран В4 и ВП также обозначили важность, как было подчеркнуто в Варшавской, Вильнюсской и Рижской декларациях, многостороннего измерения Восточного партнерства в укреплении сотрудничества между самими партнерами, а также с В4 и ЕС, включая территориальное, особенно приграничное, сотрудничество. Одним из примеров на протяжении более 15 лет является программа трансграничного сотрудничества «Польша - Беларусь - Украина», которая нацелена на поддержку процессов развития в приграничных районах Польши, Белоруссии и Украины. Первый программный период реализован в течение 2004-2006 гг. В то время структура программы и финансирование проектов были намного сложнее, чем сейчас (в Польше расходы покрывались за счет Европейского фонда регионального развития, а в Белоруссии и на Украине использовались средства ТАСИС), тем не менее было профинансировано 167 проектов, направленных на развитие

\footnotetext{
${ }^{1}$ Южный газовый коридор предусматривает поставку газа из Азербайджана через Грузию и Турцию в европейские страны. В настоящее время участниками проекта являются Азербайджан, Грузия, Турция, Греция, Болгария, Албания, и еще три балканские страны планируют присоединиться к проекту - Босния и Герцеговина, Хорватия и Черногория. Проект стартовал в мае 2018 г.
}

Современная Европа, 2018, № 7 
приграничья, на сумму 45,8 млн евро. Программный период 2007-2013 гг. был реализован в рамках Европейского инструмента соседства и партнерства (ЕИСП). Финансирование из бюджета ЕС было значительно увеличено - до 170 млн евро. С использованием этих средств было реализовано 117 проектов. Это были крупные инфраструктурные, обычные и зонтичные проекты. Их реализация позволила провести многочисленные улучшения в таких сферах, как социальная инфраструктура, здравоохранение, образование, туризм, защита культурного наследия, безопасность, а также инфраструктура и услуги пограничных пунктов пропуска. В программном периоде 2014-2020 гг. программа функционирует в рамках Европейского инструмента соседства (ЕИС). ЕИС поддерживает устойчивое развитие вдоль внешних границ ЕС, помогает уменьшить различия в стандартах уровня жизни и решить проблемы по обе стороны этих границ. Программа «Польша-БеларусьУкраина» является самой большой ЕИС программой ТГС на границах ЕС. 165 млн. евро будет выделено на проекты, направленные на защиту и продвижение культурного и природного наследия приграничных регионов, инфраструктурную доступность регионов, улучшение логистики пограничных пунктов пропуска, процедур и услуг, которые там оказываются, равно как и развитие здравоохранения и служб защиты населения [Программа PL - BY - UA 2014-2020]. Похожая инициатива действует между Венгрией - Словакией - Румынией и Украиной. Программа была запущена в 2007 г. В период с 2008 до 2014 г. на ее реализацию Европейский союз выделил более 68 млн евро из средств программы Европейской политики соседства. Приоритетными направлениями являются экономическое и социальное развитие, защита окружающей среды, повышение эффективности развития приграничных регионов и поддержка общественного сотрудничества [Information about the Programme...].

Партнеры В4 считают, что поддержка устойчивого развития вдоль внешних границ ЕС, снижение различий в уровне жизни (включая доступ к широкополосному Интернету и снижение тарифов на роуминг), решение общих проблем безопасности и расширение контактов между людьми через эти границы занимают важное место среди приоритетов сотрудничества со странами ВП. Поощрение программ трансграничного сотрудничества с увеличенным финансированием ЕС должно оставаться ключевым элементом в реализации стратегических целей Восточного партнерства [Joint Statement of the Ministers of Foreign Affairs...].

$* * *$

Страны Вишеградской группы оказывают программе «Восточное партнерство» значительную поддержку. Об этом свидетельствуют не только декларации группы, но и реализуемые в рамках программы «Восточное партнерство» инициативы вишеградских стран. Одной из предпосылок такой формы поддержки ВП является то, что с данным проектом они связывают стабильность и экономическое развитие восточных соседей в Европе и на Южном Кавказе. 
Действия, предпринимаемые странами Вишеградской группы, являются выражением стремления к увеличению своего вклада в реализацию программы «Восточное партнерство». Страны В4 претерпели уникальный процесс преобразований и европейской интеграции, из которого восточные партнеры могли бы извлечь пользу для применения в своих процессах преобразования и европейской интеграции. Вишеградское сотрудничество можно рассматривать как пример позитивного многостороннего регионального взаимодействия во всех областях. Контакты стран ВП с В4 позволяет вовлеченным участникам наиболее эффективно решать общие региональные проблемы, экономить ресурсы и укреплять взаимное доверие.

Несмотря на важность налаживания экономических отношений сегодня страны Вишеградской группы не могут предложить странам ВП никаких совместных инициатив, поскольку сами не ведут единой экономической политики. Каждая страна в данной области действует самостоятельно. Совместный поиск решения экономических проблем, существующих в странах ВП, в будущем, помог бы не только стабилизировать экономики стран ВП, но и повлиять на значение «четверки» в Европейском Союзе.

\section{Список литературы}

Pyziak-Rapacz A., (2014) Bezpieczeństwo energetyczne Rumunii, [w] „Bezpieczeństwo: teoria i praktyka”, nr 8/3, Krakowska Szkoła Wyższa im. A.F. Modrzewskiego, Kraków 2014

Борко Ю.А. (2018) Восточное партнерство: проект, реальность, будущее. М.

Восточное партнёрство до и после Вильнюса (2014). Доклады Института Европы № 301. М.

Громыко Ал..А. (2015) Взлёты и падения отношений России и Евросоюза // Современный мир и геополитика, M.,: URL: http://www.instituteofeurope.ru/images/stories/structura/gromyko/gromyko55.pdf (accessed 19.11.2018)

Программа PL - BY - UA 2014-2020. URL: https://www.pbu2020.eu/by/pages/135 (accessed 19.11.2018) $6(66)$

Шишелина Л.Н. (2015) Вишеградская четверка: 25 лет на карте Европы. Современная Европа. №

\section{References}

Azerbajdzhan otkryl gazoprovod $\mathrm{v}$ Evropu $\mathrm{v}$ obhod Rossii i Ukrainy, URL: https://www.segodnya.ua/economics/enews/azerbaydzhan-otkryl-gazoprovod-v-evropu-v-obhod-rossii-iukrainy-1142213.html (accessed 23.11.2018)

Budżet UE: UE gotowa do realizacji swoich ambicji ważnego gracza na arenie międzynarodowej, http://europa.eu/rapid/press-release_IP-18-4086_pl.htm (accessed 23.11.2018)

Eastern Partnership Transport Panel,

https://ec.europa.eu/transport/themes/international/european_neighbourhood_policy/eastern_partnership/trans port-panel_en (accessed 23.11.2018)

Flagship Projects, http://old.visegradfund.org/v4eap/flagship/ (accessed 22.11.2018)

Moldova nachnet zavtra import gaza iz Rumynii, https://noi.md/ru/news_id/57178 (accessed 19.11.2018)

Nowy wymiar Partnerstwa Wschodniego?, https://ec.europa.eu/poland/news/170412_hahn_V4_pl (accessed 19.11.2018).

Orędzie o stanie Unii 2016 r.: Europejski plan inwestycji zewnętrznych, europa.eu/rapid/pressrelease_MEMO-16-3031_pl.pdf (accessed 23.11.2018)

Rules for the Preparation, Selection, Approval and Implementation of V4EaP Extended Standard Grants Financed by the International Visegrad Fund, http://old.visegradfund.org/wordpress/wpcontent/uploads/download/rules/extended-standard-v4eap_rules_2014.pdf (accessed 22.11.2018) 
Rules for the Preparation, Selection, Approval and Implementation of the Visegrad University Studies Grants Financed by the International Visegrad https://www.visegradfund.org/archive/documents/visegrad-university-studies-grants/ (accessed 22.11.2018)

Rules of the Visegrad Scholarship Program, http://www.mladiinfo.eu/wpcontent/uploads/2014/10/v4fund-VSP-rules.pdf (accessed 22.11.2018)

The Visegrad Group Foreign Ministers' Joint Statement on the V4/IVF activities towards the Eastern Partnership, http://www.visegradgroup.eu/on-v4-ivf-activities-twrds-eap (accessed 23.11.2018)

Ukraina nachala zakupat' gaz v Vengrii. URL: https://ru.delfi.lt/abroad/global/ukraina-nachala-zakupatgaz-v-vengrii.d?id=61019019 $($ accessed 19.11.2018)

Ukraina za 1000 dnej importirovala iz Slovakii bolee $27 \mathrm{mlrd} \mathrm{m} 3$ prirodnogo gaza. URL: http://oilreview.kiev.ua/2017/05/29/ukraina-za-1000-dnej-importirovala-iz-slovakii-bolee-27-mlrd-m3prirodnogo-gaza/ (accessed 19.11.2018)

V mae Ukraina uvelichila import gaza cherez Pol'shu na 26,5\%. URL: https://ukranews.com/news/198165-v-mae-ukrayna-uvelychyla-ymport-gaza-cherez-polshu-na-265 (accessed 19.11.2018)

Visegrad Group, http://www.visegradgroup.eu (accessed 19.11.2018)

\section{Participation of the Visegrad Group countries in the implementation of the Eastern Partnership} programme

Author. Kotulewicz-Wisińska K., PhD, Assistant Professor in Department of the Political Science, Cracow University of Economics. Address: Uniwersytet ekonomiczny w Krakowie, ul. Rakowicka 27, 31-510 Kraków. E-mail: kotulewk@uek.krakow.pl

Abstract. In 2019, the tenth anniversary of the launch of the Eastern Partnership program will be celebrated. From the launch until the end of 2012, the level of multilateral cooperation in the Eastern Partnership program functioned fairly well. Since 2013, the bilateral relations of the European Union with its eastern neighbors primarily prevail. In this regard, special attention should be paid to the relations of the Visegrad Group countries with the countries of the Eastern Partnership. Despite the fact that Poland has always shown the greatest interest in the program itself, Hungary, Slovakia and the Czech Republic, because they are also countries bordering the countries covered by the program, have joined the realization of the objectives of this initiative. And today, the Eastern Partnership countries occupy an important place in the foreign policy of the Visegrad Group countries. It should be borne in mind that the Czech Republic, Poland, Slovakia and Hungary - the countries of the Visegrad Group - for the eastern neighbors can serve as an example of the transformation of society, the construction of the state and the strengthening of relations with the West. At the moment, for the countries of the Visegrad Group, a very important aspect of cooperation with the countries of the Eastern Partnership is the strengthening of relations. General actions of the B4 countries can be aimed at building a strong civil society in the EaP countries, supporting local initiatives, developing independent journalism and other initiatives leading to the democratization of countries covered by the Eastern Partnership program. The purpose of this article is to analyze which initiatives of the B4 countries are implementing in the Eastern Partnership countries that contribute to the implementation of the above-mentioned goals.

Key words: Visegrad Group, Eastern Partnership countries, International Visegrad Fund, flagship initiatives, training programs, relations at the interpersonal level, cross-border cooperation, energy security, cooperation in the field of transport.

DOI: http://dx.doi.org/10.15211/soveurope72018101114 